\title{
Correction to: Efficacy of oral rosuvastatin intervention on HDL and its associated proteins in men with type 2 diabetes mellitus
}

\author{
Sriram Naresh ${ }^{1} \cdot$ Aparna R. Bitla $^{1}$ - P. V. L. N. Srinivasa Rao ${ }^{1} \cdot$ Alok Sachan $^{2} \cdot$ Yadagiri Lakshmi Amancharla $^{3}$
}

Published online: 13 October 2020

(c) Springer Science+Business Media, LLC, part of Springer Nature 2020

Correction to: Endocrine

https://doi.org/10.1007/s12020-020-02472-5

The original version of this article unfortunately contained a mistake in "Results" section.

The sentence "Majority of the study participants; $n=38$ $(95.0 \%)$ were on treatment with metformin while only one each $(2.5 \%)$ were on glycomet and on ayurvedic treatment at the time of recruitment". should read as "Majority of the study participants; $n=39(97.0 \%)$ were on treatment with metformin while only one (3\%) was on ayurvedic treatment at the time of recruitment".

The original article has been corrected.

Publisher's note Springer Nature remains neutral with regard to jurisdictional claims in published maps and institutional affiliations.
The original article can be found online at https://doi.org/10.1007/ s12020-020-02472-5.

$\triangle$ Aparna R. Bitla

aparnabitla@yahoo.co.in

1 Department of Biochemistry, Sri Venkateswara Institute of Medical Sciences, Tirupati, Andhra Pradesh 517507, India

2 Department of Endocrinology and Metabolism, Sri Venkateswara Institute of Medical Sciences, Tirupati, Andhra Pradesh 517507, India

3 Department of Radiology, Sri Venkateswara Institute of Medical Sciences, Tirupati, Andhra Pradesh 517507, India 